\title{
كتابات عبد الوهاب المسيري: المداخل الكبرى لولوج فكره
}

*عبد القادر مرزاق

$$
\begin{aligned}
& \text { الملخص } \\
& \text { سعت الدراسة إلى تحديد المداخل الكبرى في فكر المسيري، معتقدة أن كتاباته تتأسس على مفاهيم مفاتيح، } \\
& \text { ويتعذر فهم تفاصيلها ما لم ندركها. من هذه المفاهيم المفاتيح: التوحيد بوصفه يحل إشكالية ثنائية؛ الله، الإنسان؛ } \\
& \text { فتنجلي من خلال الدراسة صفات الله الخالق، وصفات الإنسان المخلوق. ومنها مفهوم الحلولية؛ وهي الطرف المناقض }
\end{aligned}
$$

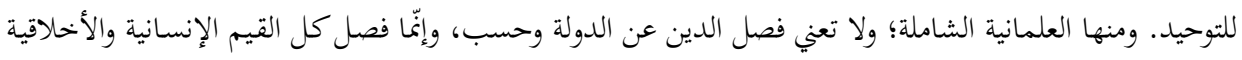

$$
\begin{aligned}
& \text { والدينية عن حياة الإنسان في جانبيها العام والخاص. } \\
& \text { الكلمات المفتاحيـة: عبد الوهـاب المسيري، التوحيد، الحلولية، النموذج المعرفي، العلمانية الشـاملة، العلمانية } \\
& \text { الجزئية، رؤية العالم. }
\end{aligned}
$$

\section{Abdelwahab El-Messiri's Writings: Major entries to his thought}

Abstract

The study sought to identify the major entries in El-Messiri's thought, believing that his writings are based on key concepts, which are necessary to understand it. One of these key concepts is: tawhid (monotheism) which solve the duality of God and man; through clear distinction between God the Creator, and man the created. Pantheism is another key concept: which is the opposite of tawhid. Comprehensive secularism is a third concept and does not mean only separation of religion and state, but separation of all human, moral, and religious values, from all sectors o human public life; public private.

Keywords: Abdelwahab El-Messiri, tawhid, pantheism, paradigm, comprehensive secularism partial secularism, worldview.

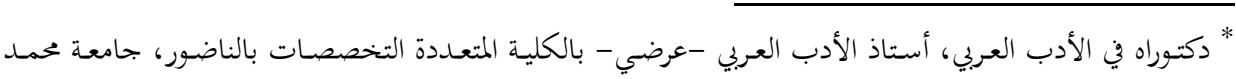

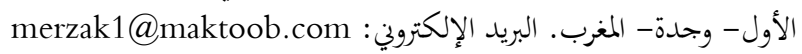

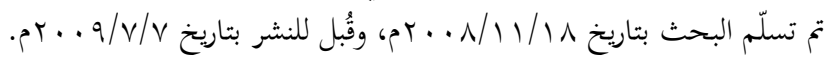


مقدمة:

تسعى هذه الورقة إلى تكثيف المفاهيم وتركيبها، على نحوِ يتلاءم وما سأقترحه مـن

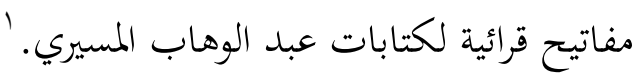

وأكاد أجزم، من خلال متابعتي لكتابات المرحوم المسيري منذ ما يربو على عقد من

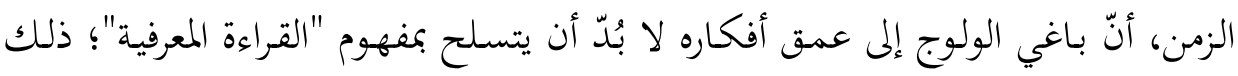

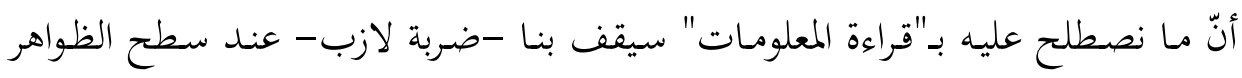

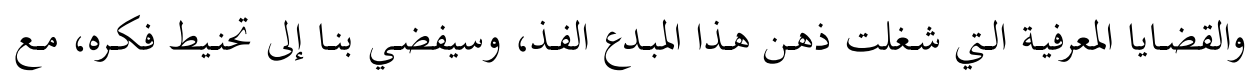

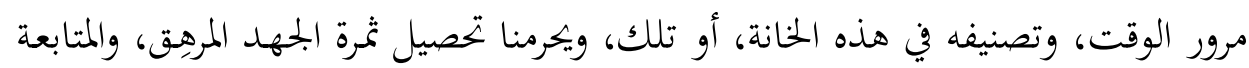

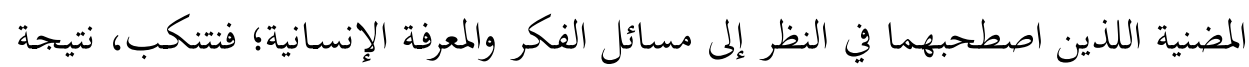

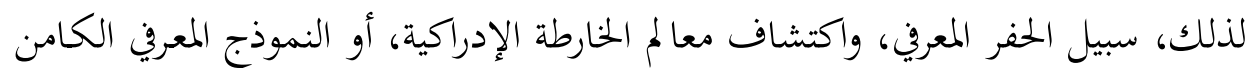

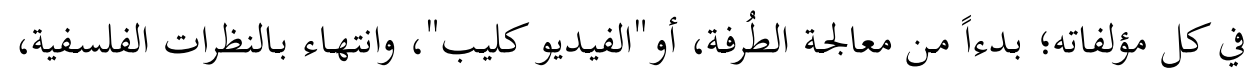

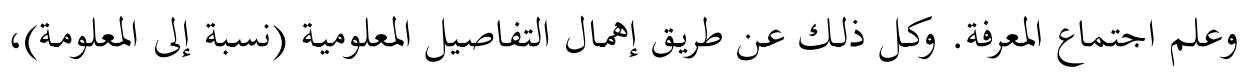

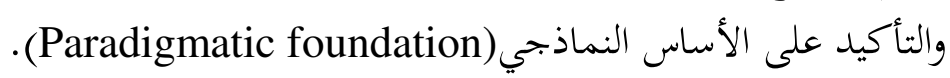

فما المداخل الكبرى إذن التي نرى أفها عون لنا على الإمساك بخيوط هذه الشبكة

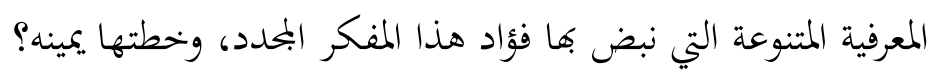

\section{أولاً: مدخل التوحيد}

قد يستغرب بعض القراء، ويستنكر هـذه "المصادرة" التي نزعم أفّّا المـدخل الأول لقراءة كتابات المسيري قراءة معرفية؛ تحصّل الكلي، وتتجاوز رصف المعلومات.

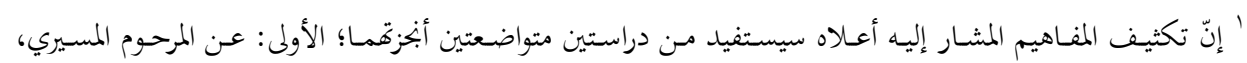

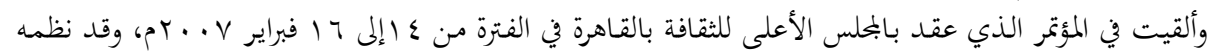

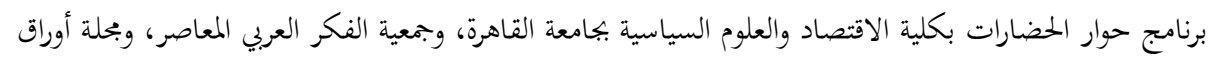

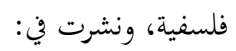

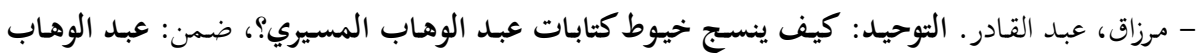

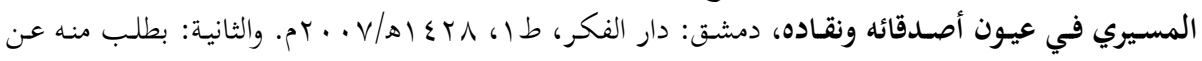

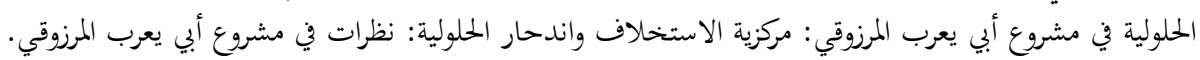

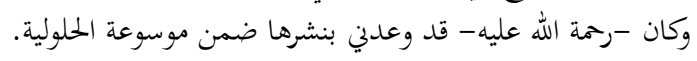




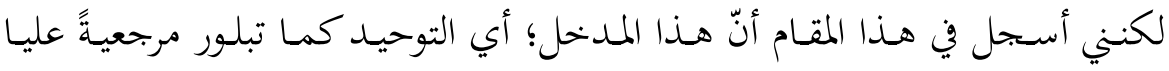

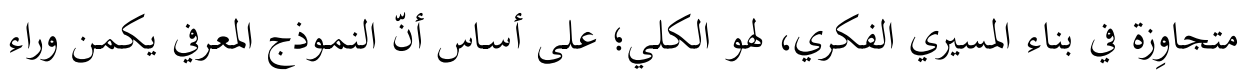

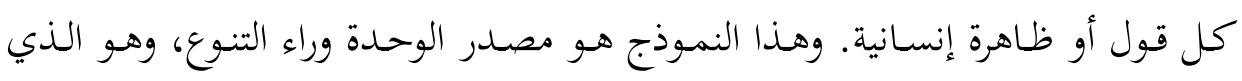

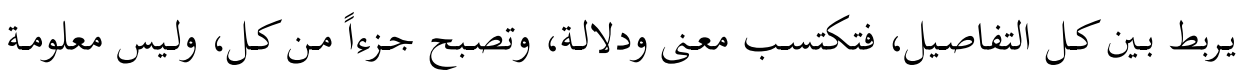

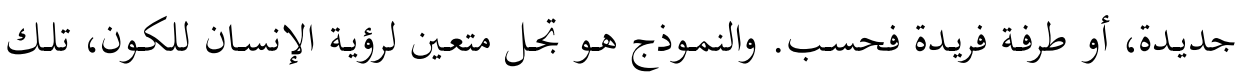

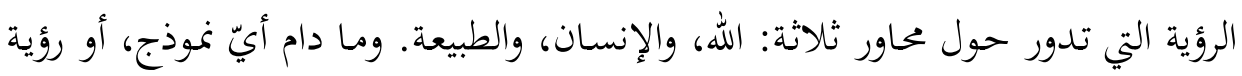

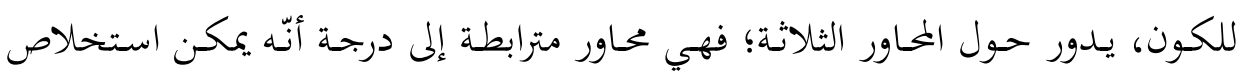

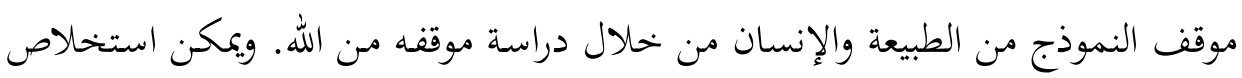

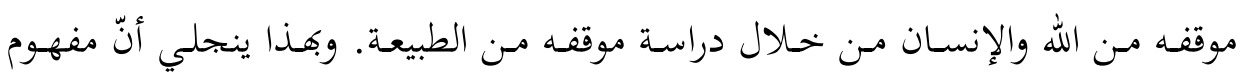

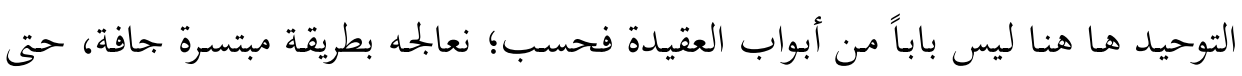

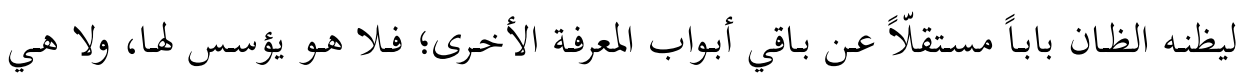
تستند إليه.

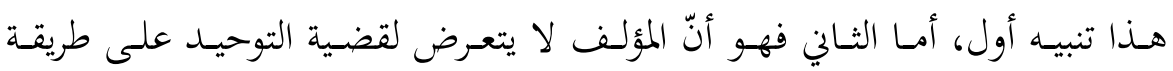

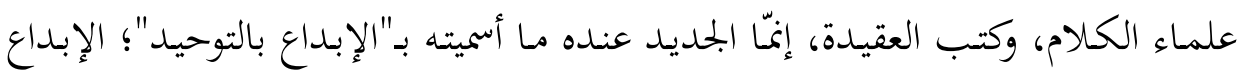

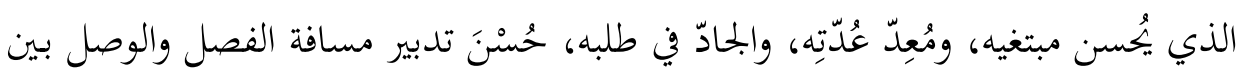

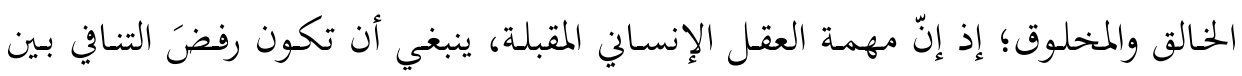

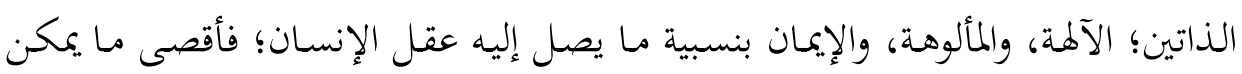

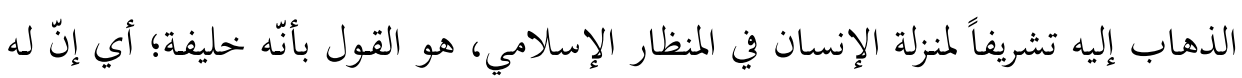

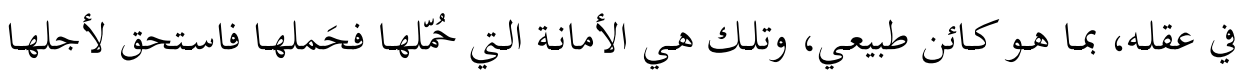

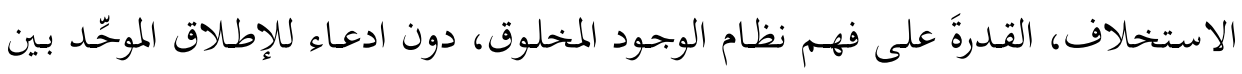

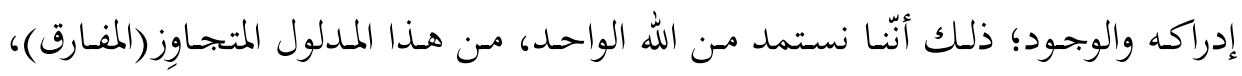

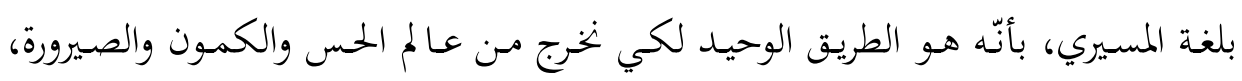

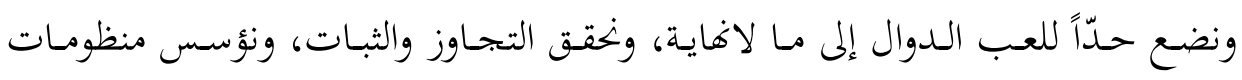
فلسفية ومعرفية وأخلاقية. 
نخلق مثل هذه المنظومـات، ونحد مـن بتحني بعض الرؤى الفلسفية في زعمها ركوب

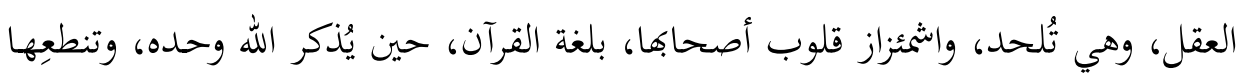

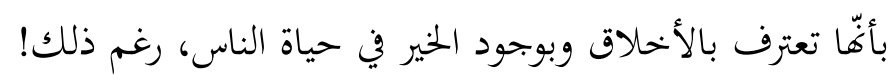
فلنصغ إلى أحد أصحاب هذه الرؤى وهو يقرر مع الزعم الأول؛ إذ يقول: إنّ العلة

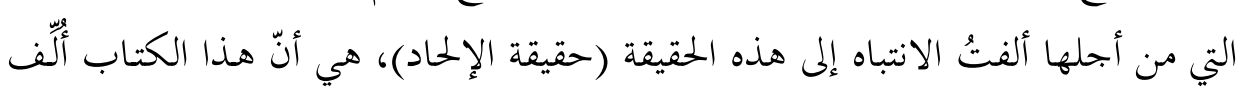

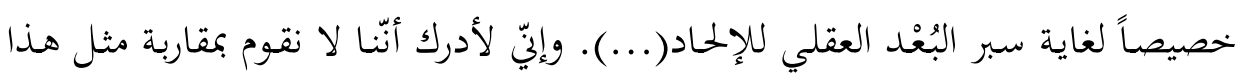

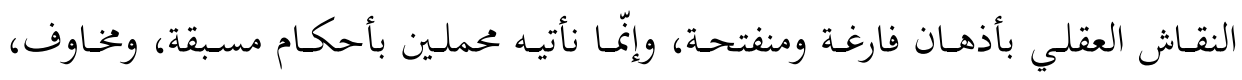

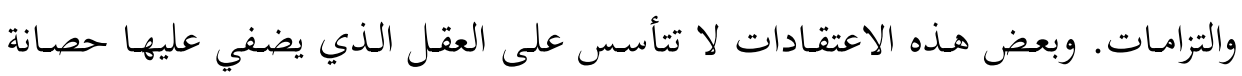

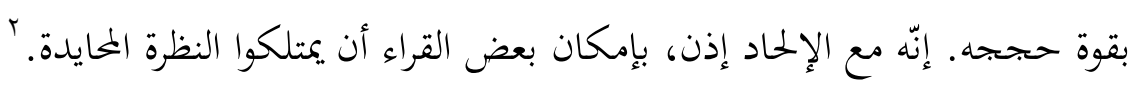
ونلفيـه يسجل مـع التنطع الثـاني: إن حـدّ الإلحـاد، في الحقيقـة، بسيط للغايـة؛ فهو

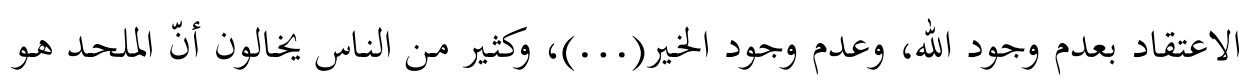

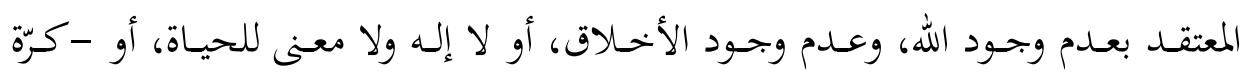

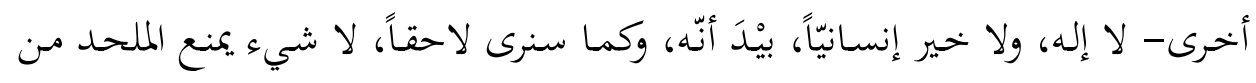

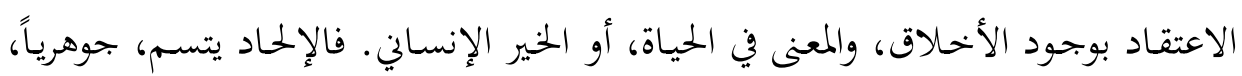

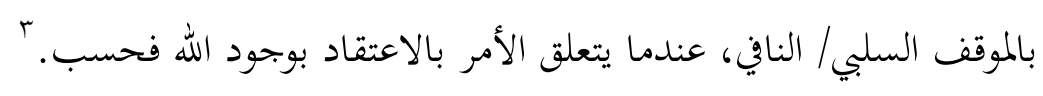
هكذا يمكنتـا أن هتـدي مـن خهلال كتابـات المسـيري، في حسدود مـا يتـاح للعقـل البشـري، إلى توحيـد الله؛ فيتجسـد ذلك في استحضـار تـدبيره في معرفتنـا؛ إذ الممارسـات العقلية أو النفسية أو الجسدية لا نقف فيها عند ظاهرها فحسب، وإنّما نتوغل إلى ما هو

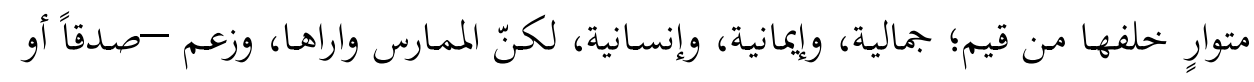

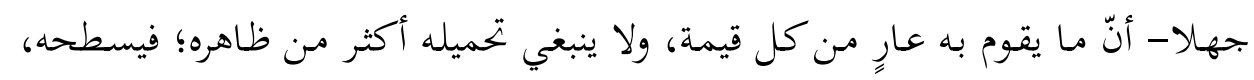
ويعلن موت ما هو سري وراءه، يحفظ له وجوده المستقل عن أذهاننا، ويجيل على غناه،

2 Baggini, Julian. Atheism, a very short introduction, Published in the United States by Oxford University Press Inc, New York, 2003, p3.

${ }^{3}$ Ibid, p3. 
وعلى بهجة المعرفة فيه حين نكتشف، على اختلاف الأزمنة والأمكنة، أنّا عرفنا جديداً عنه وفيه.

وبـذلك، وفق مـدخل التوحيد كمـا نوهـت، فبإنّ الإنسـان يـركك بعض هـذا الوجـود

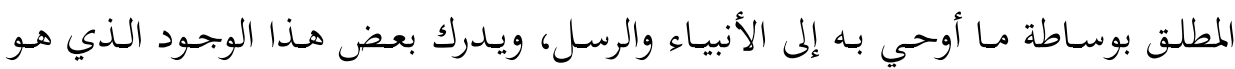
خليفة فيه بوساطة مداركه العقلية والوجدانية، ولن تتساوى في يوم من الأيام مداركه تلك

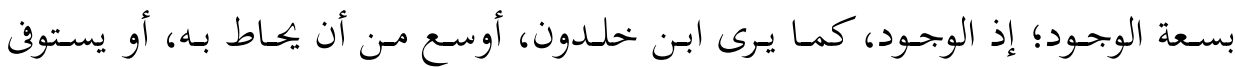
إدراكه بجملته؛ روحانيّاً، أو جسمانيّاً.

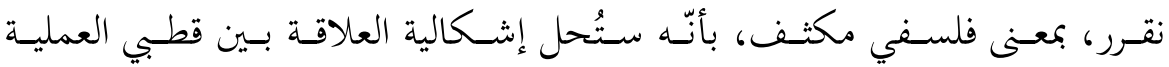
التواصلية؛ -عموديّاً إذا جاز التعبير - الله تعالى؛ الخالق الآمر، والإنسان؛ المخلوق العابد، وأفقيّاً -إذا جاز التعبير أيضاً-؛ أي الإنسان، والطبيعة؛ نتيجةً مترتبة عن العلاقة الأولى. وبهذا، في ظل مداخل التوحيد، كما نفهم منه مرجعية عليا فائية تسند ظهر كل حركة سلوكية بسيطة، أو معرفية متفلسفة، نحن أمام نوعين من الوضع؛ مطلق، ونسبي. إلهي، وإنساني:

الأول هو الوضع الإلهي للطبيعة وللشريعة بما هي مخلوقات على صفات أرادها الله، وليست صفات ذاتية للموصوفات.

والثاني هو الوضع الإنسـاني لعلمهما وللعمل بحسب هـذا العلهم؛ وهما علم وعمل اجتهاديان لا يزعمان أنّما عيْن الوضع الإلهي للطبيعة وللشريعة، بل ما أصابه الاجتهاد الإدراكي لمما، وليس وراء ذلك ما يتجاوز الإنسان.

وإذا نحن لم نفهم هذا الوضع، فإنبّا سنقع في مأزق خلاصته المؤكدة هي أنّه: يقع

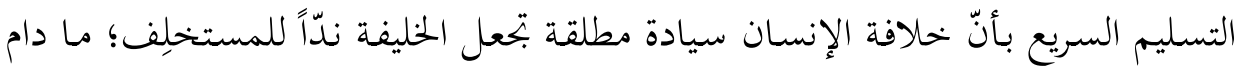

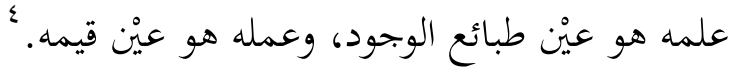

" راجع الدراسة التي أشرت إليها في المقدمة: مركزية الاستخلاف واندحار الحلولية: نظرات في مشروع أبي يعرب 


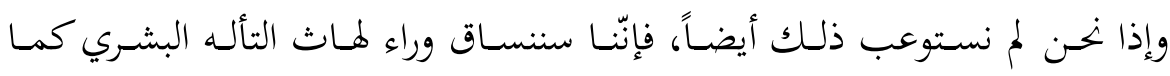

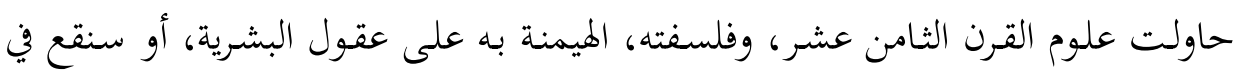

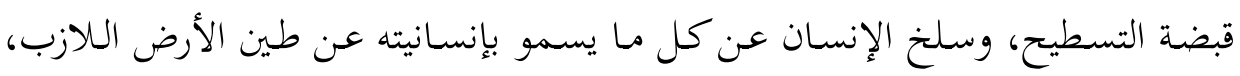

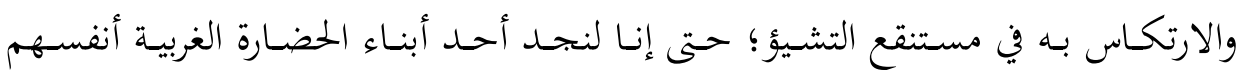

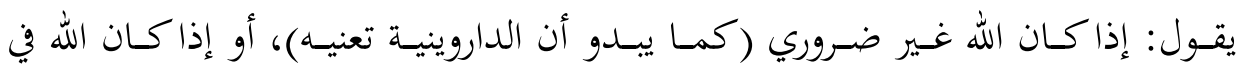

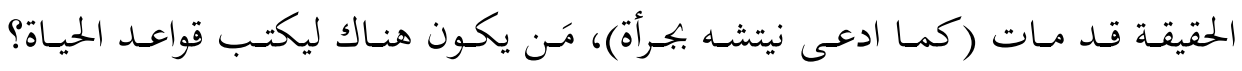

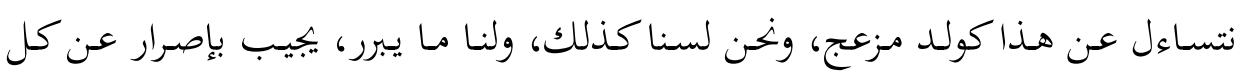

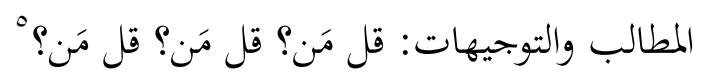

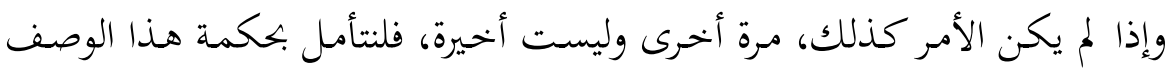

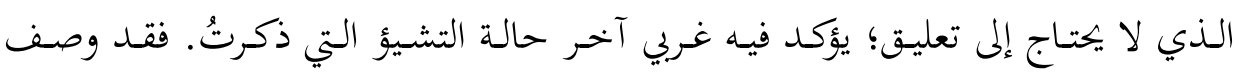

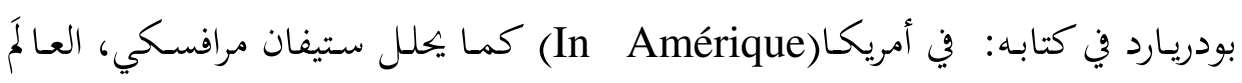
الأمريكي بأنّه عالمَ قحط روحي رهيب، ولعبة لا متناهية، وأقصى ثقل لمبل للتجربة القصيرة

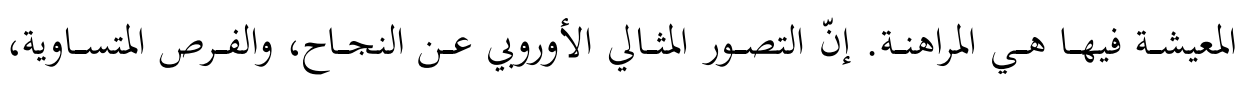

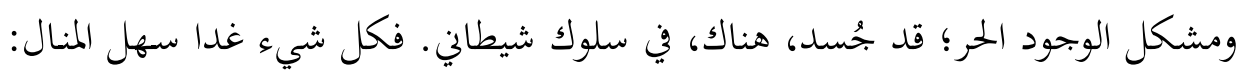

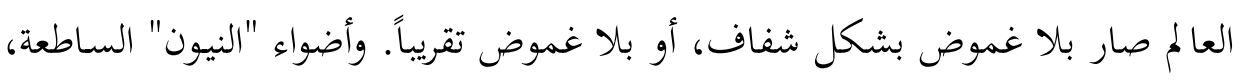

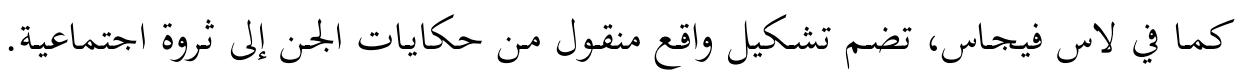

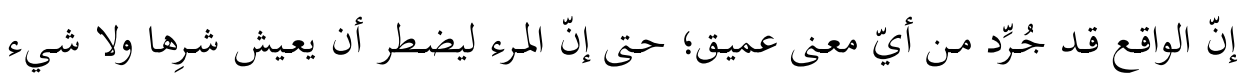
سوى ذلك.

لذلك نبادر بتأكيد أنهّ لا غرابة أنّ كل ما نفكر فيه، ونُعبِّر عنه كتابةً أو شفهيّاً؛ لا

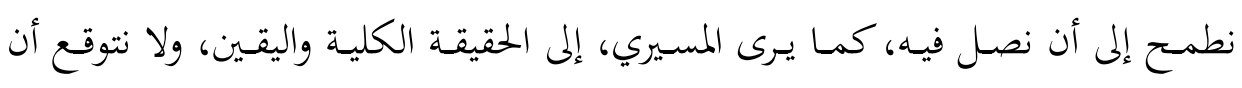

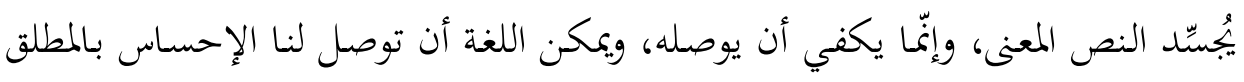

${ }^{5}$ Norman L. Geisler and Paul K. Hoffman. Why I am a Christian?: leading Thinkers explain why they believe, Published by Baker Books a division of Baker Book House Company, 2001- p13.

${ }^{6}$ Stefan Morawski. The troubles with postmodernism, With a foreword by Zygmunt Bauman - London and New York, 2003, pp8-9. 
وبعالمَ المتجاوِز دون أن تكون هي ذاتها مطلقة أو متجاوِةٍ؛ فالإفصاح الكامل والتجسد لا يتم إلّا في فاية التاريخ والزمان.

\section{ثانياً: مدخل الحلولية}

إنّ هـذا المـدخل، وهو مـا يسميه المسيري بمـذهب الحلول، أو الكمـون، أو الحلولية

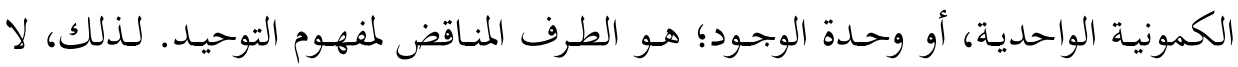
غرابة أن يخصه بدراسة ضخمة هي "موسوعة الحلولية"، ناهيك عن تسرباته في ثنايا كل مؤلفاته؛ وتفسير ذلك أنّ الرجل يمتلك نموذجاً معرفياً، ورؤية معرفية واحدة متماسكة الحكة. يذهب المسيري في هذه القضية إلى أنّ معظم رؤى العالمَ تدور حول ثلاثة عناصر،

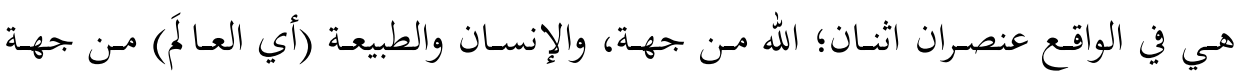

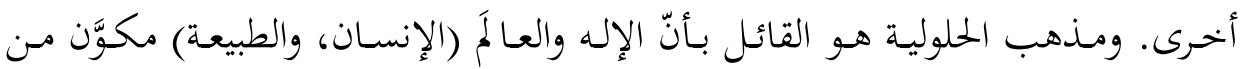

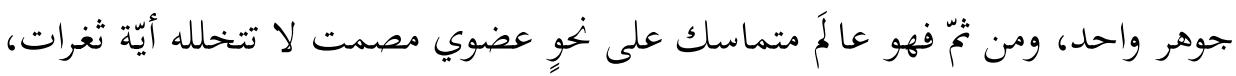

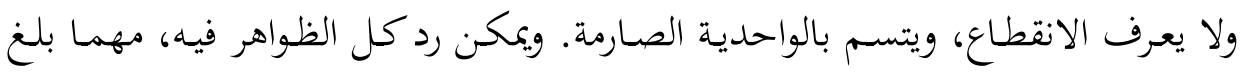

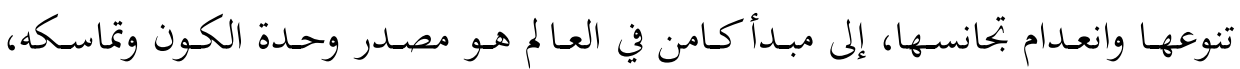
ومصدر حياته وحيويته، وهو القوة الدافعة له، الكامنة فيه، ويمكن تفسير كل شيء مـن خاله.

إنّ مـا يسميه المؤلف بـ"وحـدة الوجـود الروحيـة"، و "وحـدة الوجـود الماديـة" في إطـار

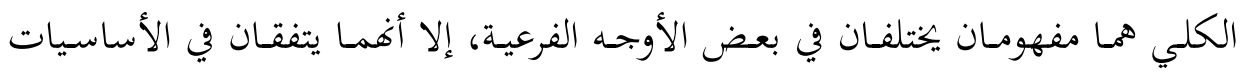
والبنيـة. ويقصد بالإطسار الكلي هنـا المعنى المنطقي؛ أي "الحلولية الكامنـة"، وقد تتبـادل المصطلحات الثلاثة الأدوار؛ أي وحدة الوجود الروحية، ووحدة الوجود الروحية، والحلولية الكامنة، فكلها تصبح كليّاً في استعمال المؤلف.

ففي منظومـات وحـدة الوجـود الروحيـة (الحلوليـة الكمونيـة الروحيـة) يسمى الجموهر

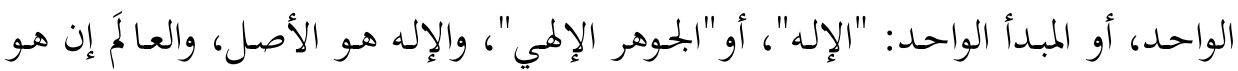
إلّال وَهْم؛ ويجري التعبير عن هذا بالقول: "حل الإله في العالمَ؛ أي في الطبيعة والإنسان". ويمكن تسمية الجهوهر الواحسد تسميات شبه روحيـة، وشبه مادية، كأن يقـال: إنّ المبـدأ 
الواحدد هو "روح الشعب"، أو "روح التـاريخ"، أو"العقل المطلق". أمّا في منظومات وحـدة

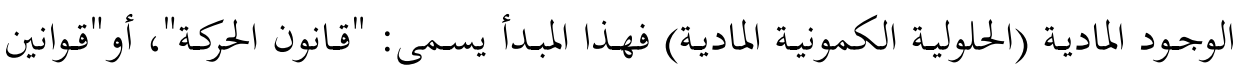

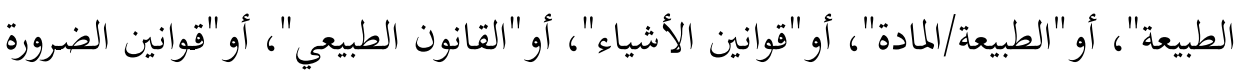

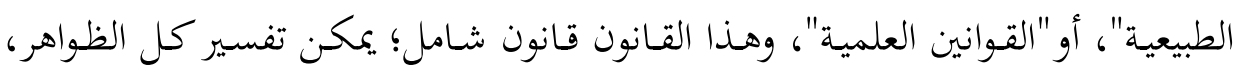
ومن بينها الظاهرة الإنسانية، من خلاله.

نسجل هنا أنّ هـاتين النظريتين في المعرفة تؤولان فعلاً إلى نتيجة واحلدة؛ هي عـذم الإله، والعياذ بالله، فقد أدى التصور في الشق المادي إلى أنّ الله يصبح علديم العين إلا إذا حـلّ في مخلوقاته ليتعـين، وأدى بمعنى ثـانٍ إلى نفي كل قيـام ذاتي للمخلوقـات، جـاعلاً أعياهـا بحرد ظلال لأفعال الذات المطلقة. وأدى في الشق الانطوائي/ الروحي، إلى الزعم

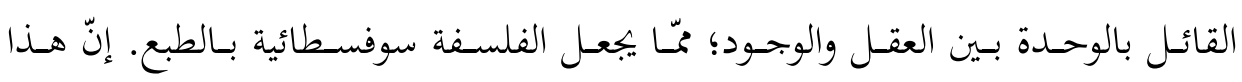
التوحيد يعود إلى القول بالإنسان مقياساً للوجود؛ أي كما يزعم "بيركلي"، ₹ مثلاً:

(Everything that exists is either a mind or depends for its existence upon a mind. Matter does not exist).

وهذا هو ما يسميه ابن خلدون الوهم الأكبر؛ ^وَهْم حصر الوجود في الإدراك، وهو

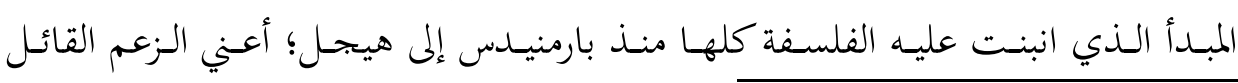
> انظر مؤلفيه:

- George Berkeley. A treatise concerning the principles of Human knowledge, Edited by David R. Wilkins 2002, based on the edition by Jacob Tonson in 1734.

- George Berkeley. three dialogues between Hylas and Philonous in opposition to Sceptics and Atheists revised and published with a treatise Concerning the Principles of Human Knowledge, 2 volumes (London J. Tonson, 1734)

وراجع:

- Solipsism and the Problem of Other Minds حرف S في (the Internet Encyclopedia of philosophy (IEP) و و مادة: George Berkeley.

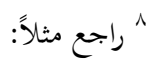

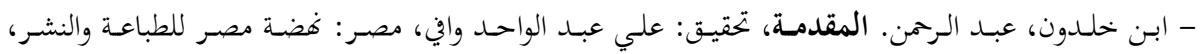


بالوحدة بين العقل والوجود؛ وهكذا لا يمكن التمييز عندئذٍ بين الإله والمألوه. وما تعريف

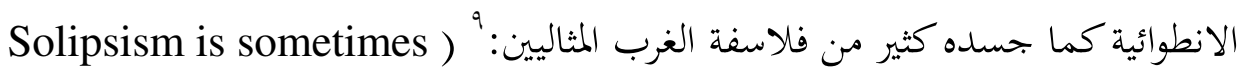
expressed as the view that "I am the only mind which exists, " or ("My mental states are the only mental states ولم نـذهب بعيـاً وأمامنـا هـذا الكتـاب الصـارخ بـدءاً بعنوانه، وانتهاءً بمـا ضـمه بـين

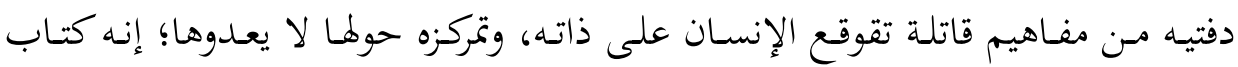

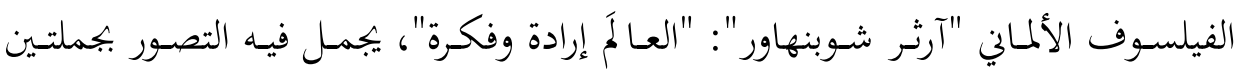

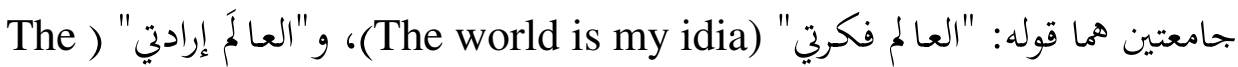
World is my will لكل شيء يحيا ويعرف، لكن الإنسان وححده بوسعه أن يجعلها تعكس الوعي وبتحرده.

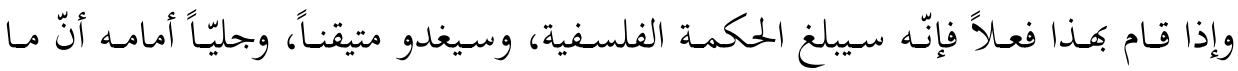

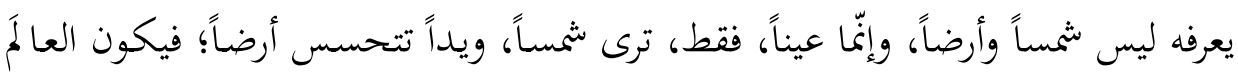

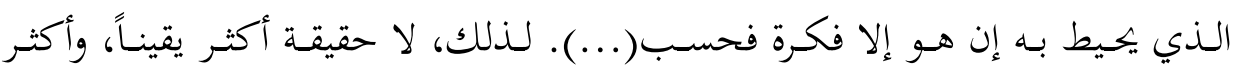

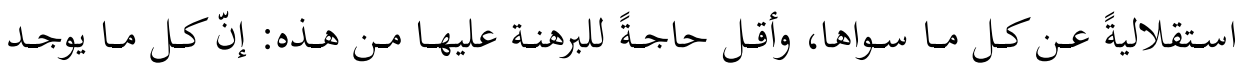

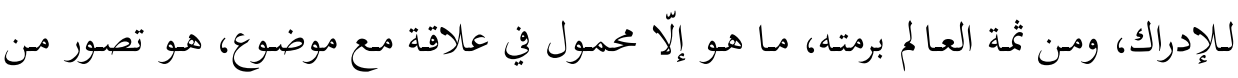

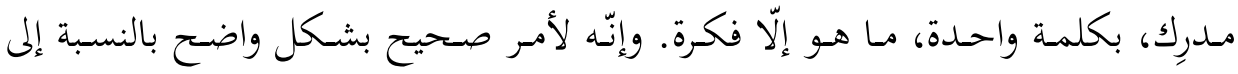

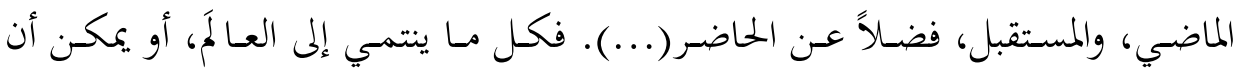

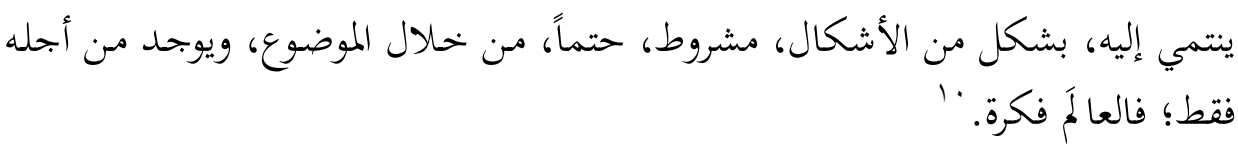

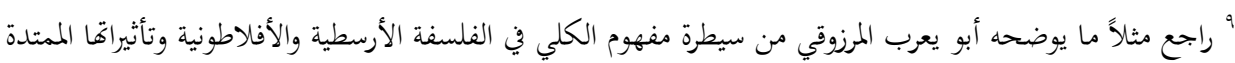

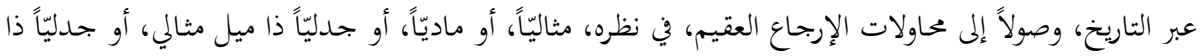

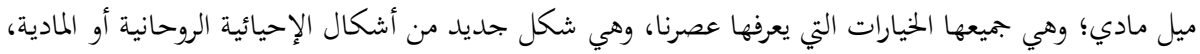

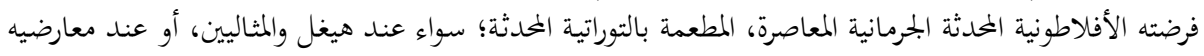

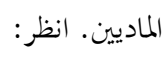

- المرزوقي، أبو يعرب. إصلاح العقل في الفلسفة العربية: من واقعية أرسطو وأفلاطون إلى اسمية ابن تيمية

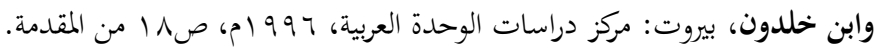

${ }^{10}$ Arthur Schopenhauer, The world as Will and Idea, Translated from the German by R. B. HALDANE, M.A.and J. KEMP, M.A. VOL. I. 


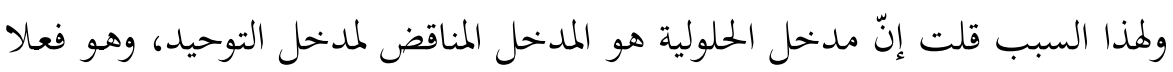

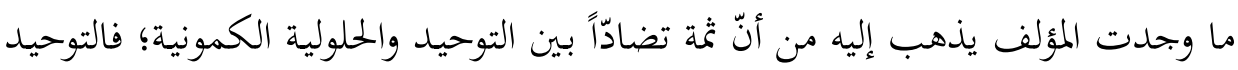

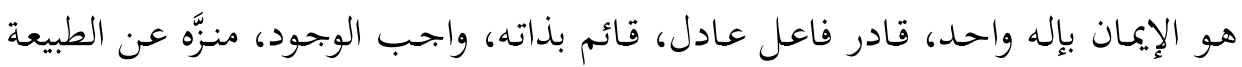

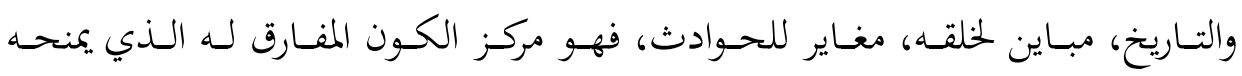

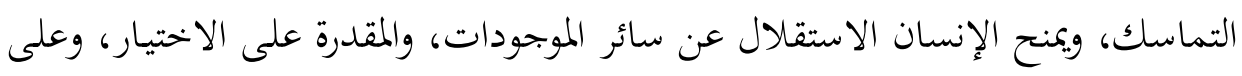

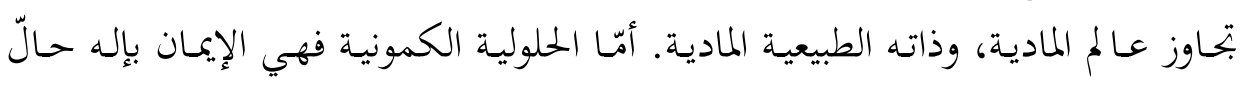
كامن في الطبيعة والإنسان والتاريخ؛ أي إنّ مركز الكون كامن فيه.

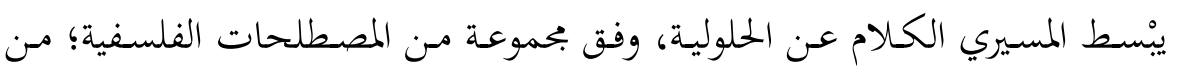

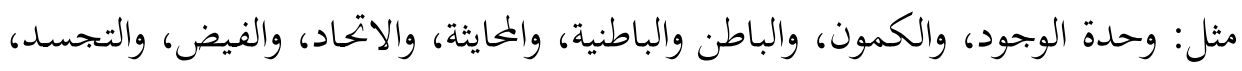

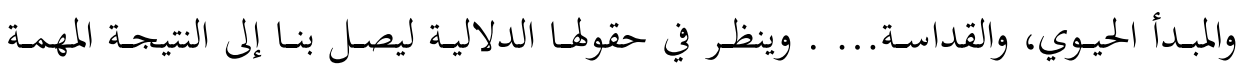

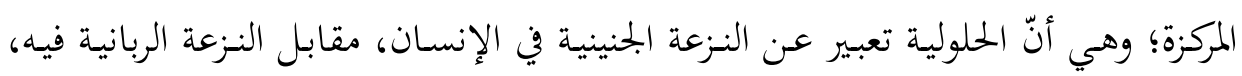

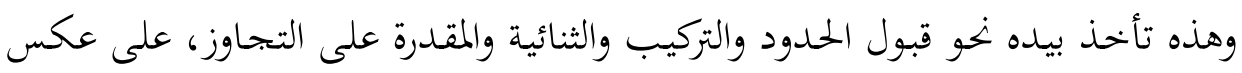

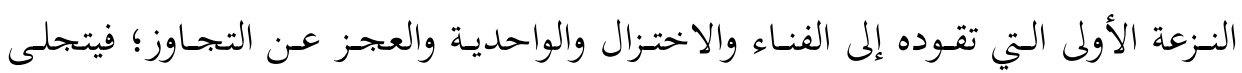

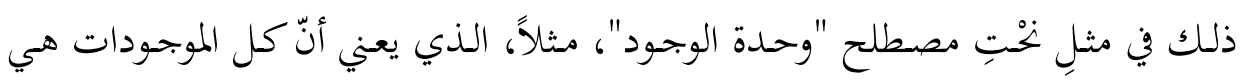

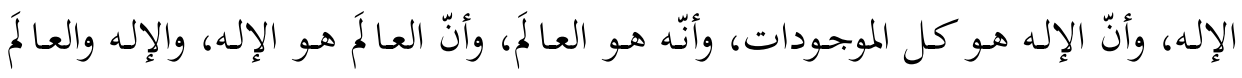

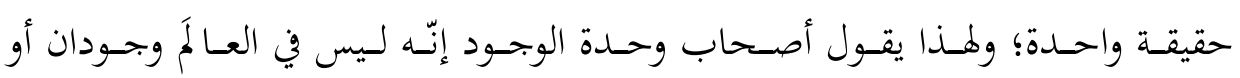
جوهران، بل هناك جوهر واحد، وهو جوهر متجاوز للإنسان.

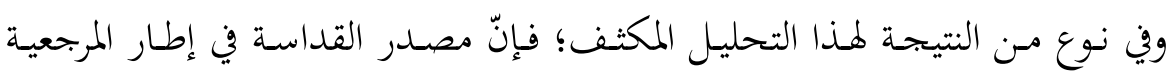

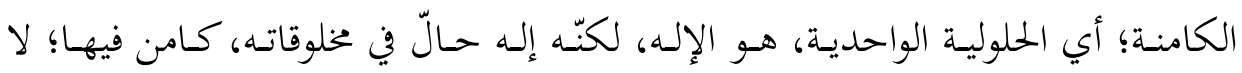

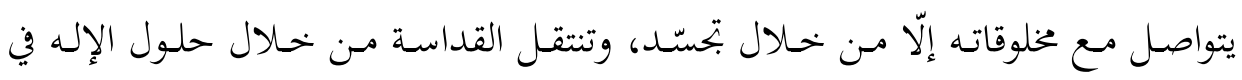

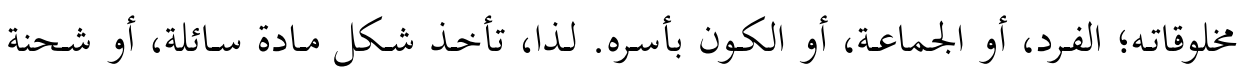

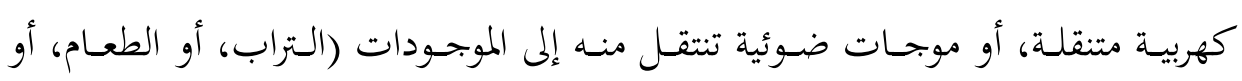
الشراب، أو النبات، أو الإنسان)؛ فتصبح القداسة كامنة فيها.

containing four books- seventh edition- London- Broadway House, 6874 CARTER LANE,E. G. first book- pp 3-4. 


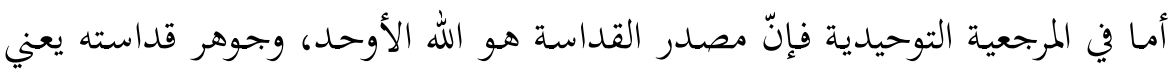

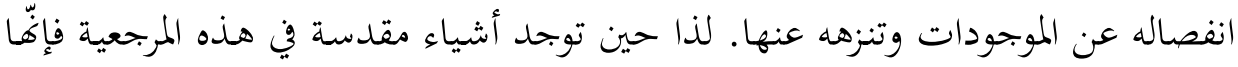

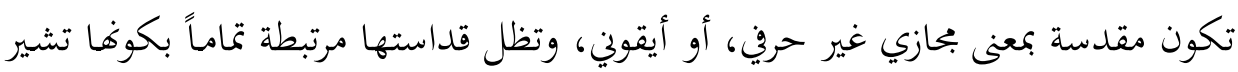

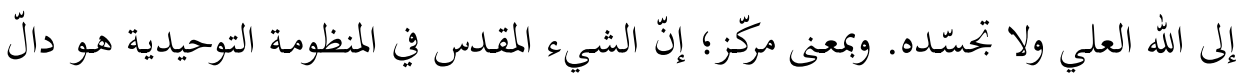

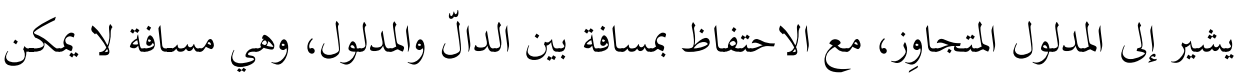

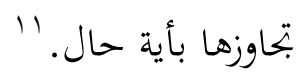

\section{ثالثاً: مدخل العلمانية الشاملة}

مفهوم العلمانية كما يؤسس له المسيري، هو المدخل الثالث الذي نلح أنّه يفك كثيراً

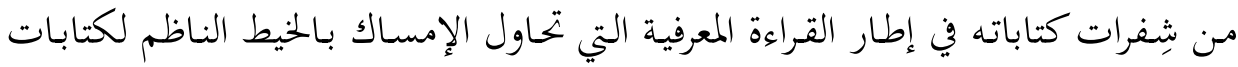

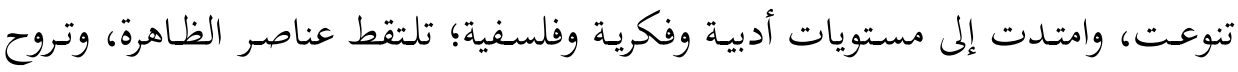

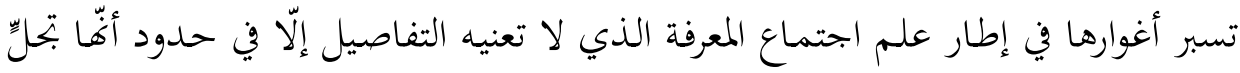

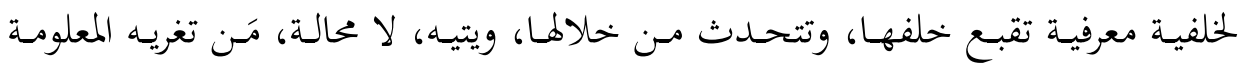

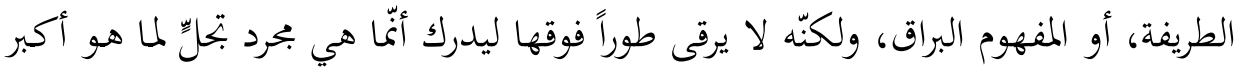

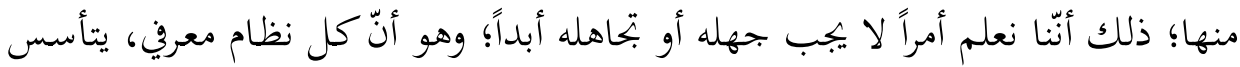

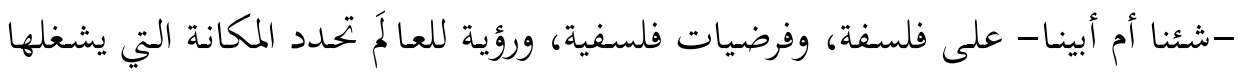

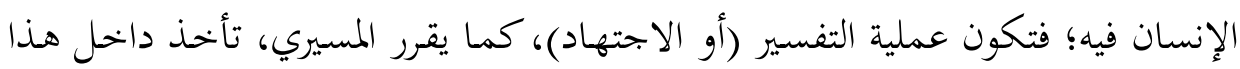

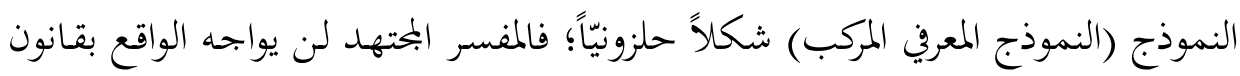

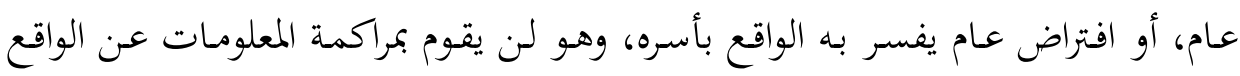

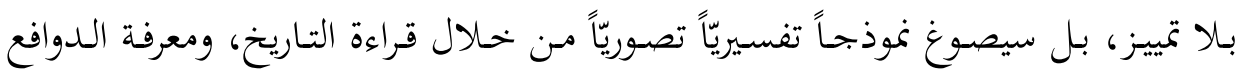

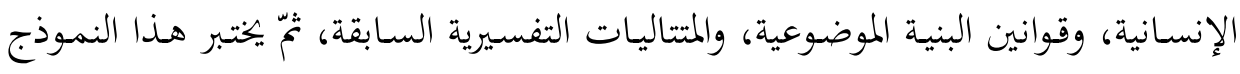

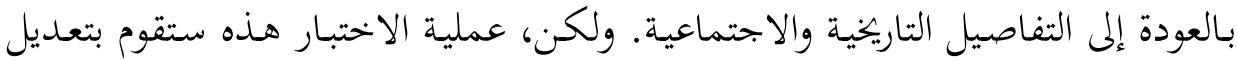

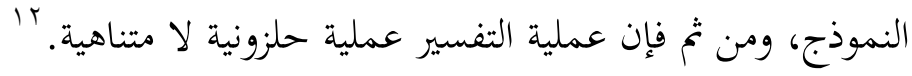

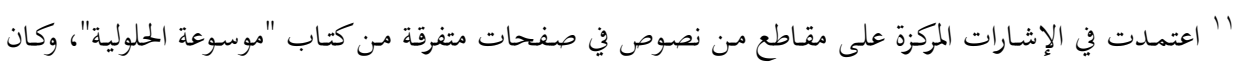

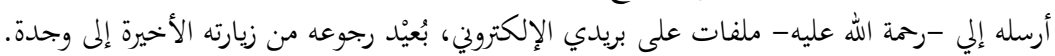

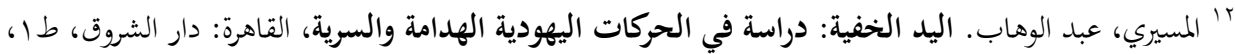

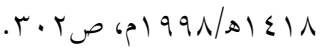




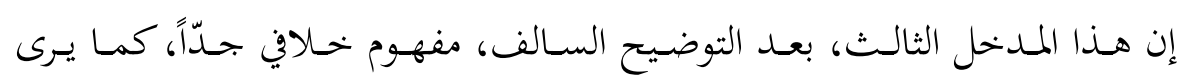

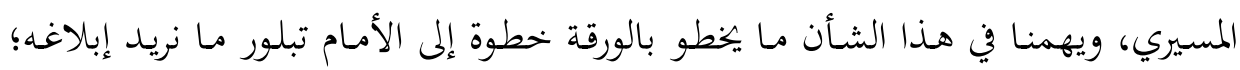

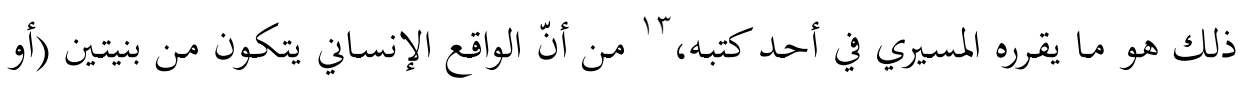

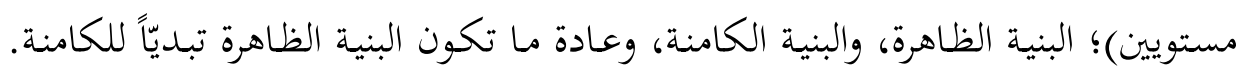

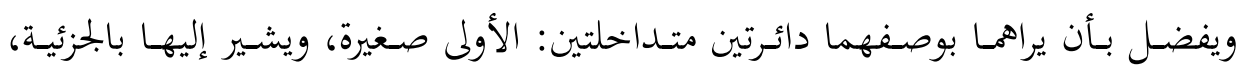

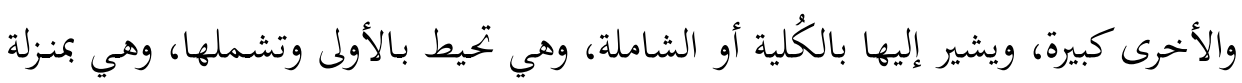

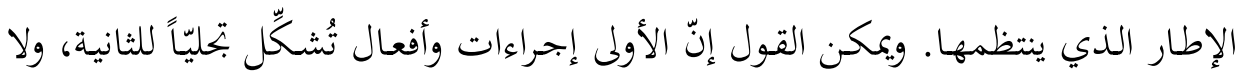

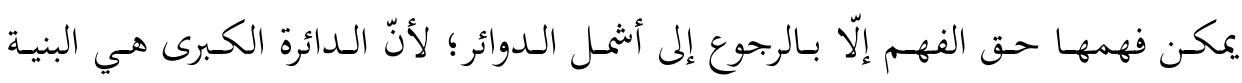
الكامنة، والمرجعية النهائية.

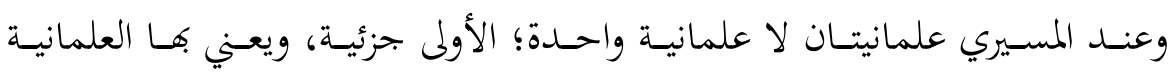

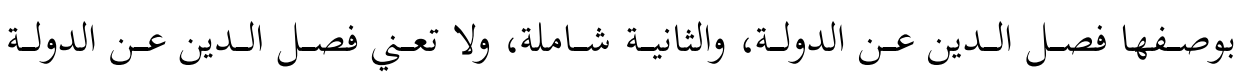

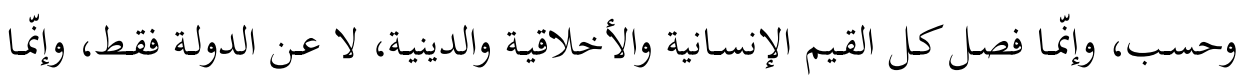

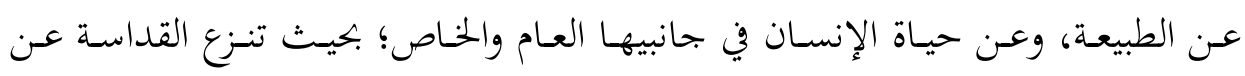

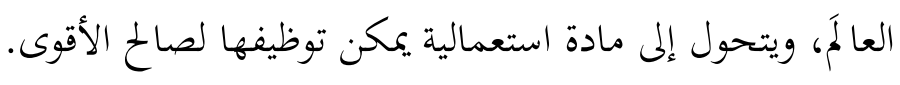

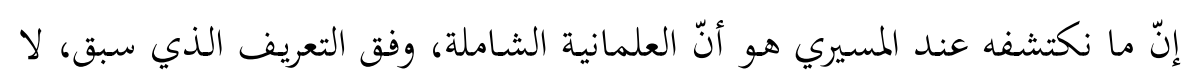

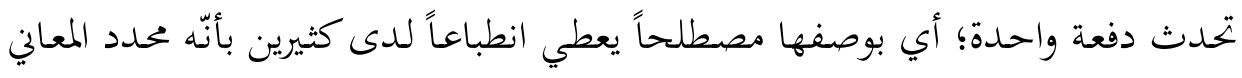

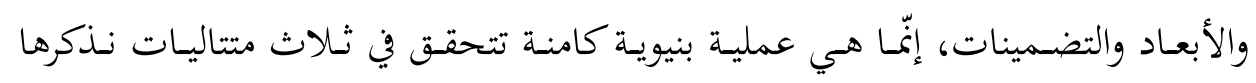
باقتضاب شديد.

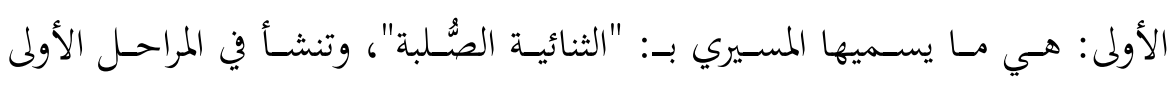

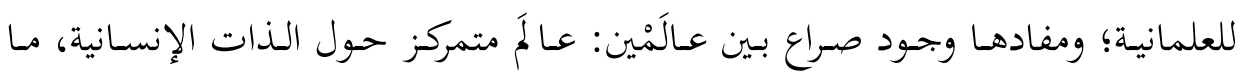

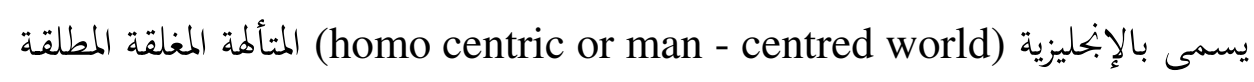
التي تصبح مرجعية ذاهما ومرجعية الكون بأسره، ويسميها الواحدية الإنسانية (الذاتية)،

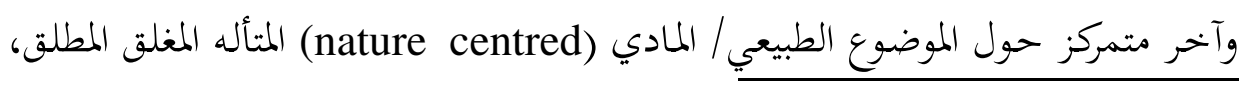

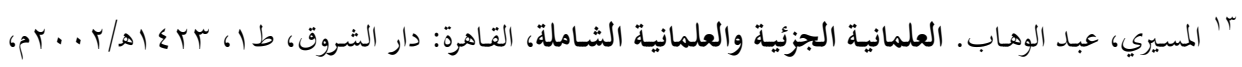


الذي يصبح مرجعية ذاته ومرجعية الكون بأسره، وهو ما يؤدي إلى ما يسميه "الواحدية

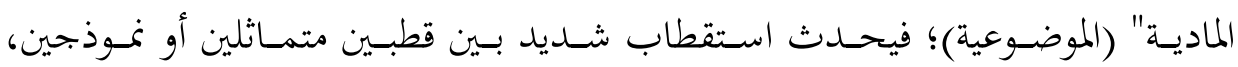

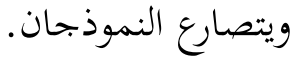
الثانية: هي ما يسميها بـ"مرحلة الصلابة"؛ فيتم "نزع القداسة عن العالَّ"، أو "نزع السحر عنه"، أو "تحييده"، وذلك في خضم التحديث الذي يصدر عن تأكيد زمنية كل

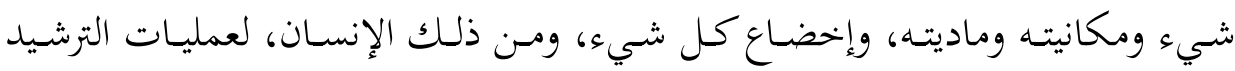

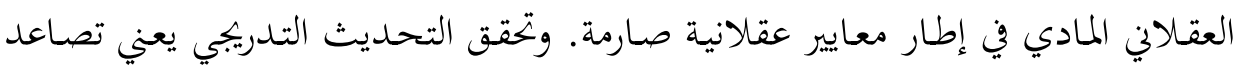

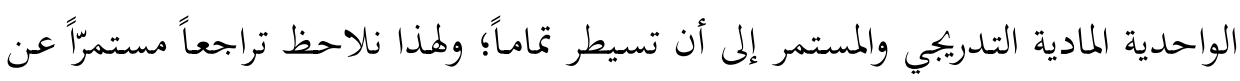
الفلسفة الإنسانية، وعن ثنائية الإنسان والطبيعية، وعن الإيمان بالثبات والتجاوز. الثالثة: هي ما يصطلح عليها بـ"مرحلة السيولة". لعلنا لاحظنا تفكيك مقولة الذات

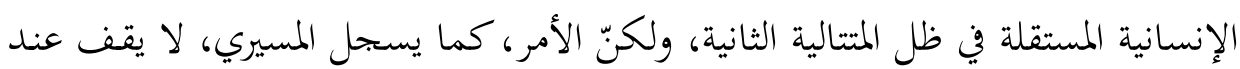

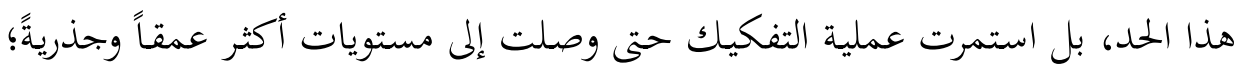

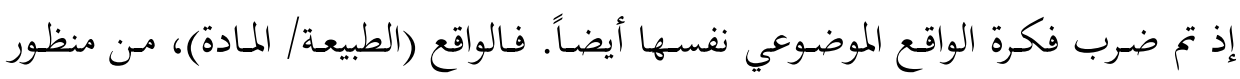

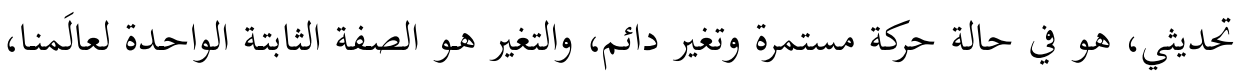
ومن تيمّ سقطت الطبيعة نفسها في قبضة الصيرورة.

وهكذا بعـد تفكيـك الـذات والموضـوع، أجابـت الحضـارة الغربيـة عـن أسئلة كانـت

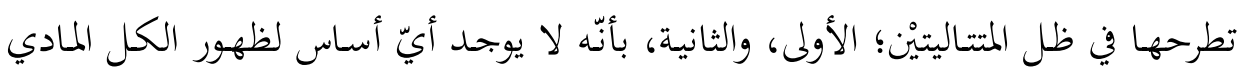

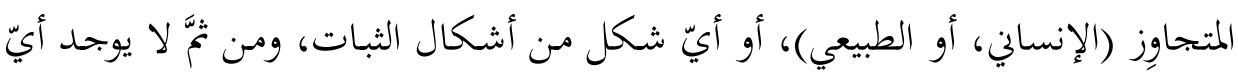

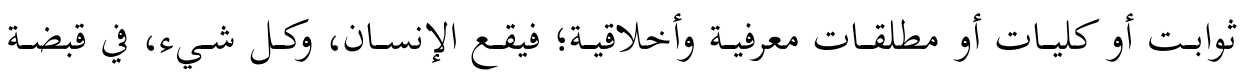
الصيرورة.

ولقد عبَّر أحد الغربيين خير تعبير عن هذا العوم في العماء؛ عوم في عالَّك كل ما هو صُلب فيه يتبدد ويغدو هباء؛ فقال: "فأن نكون من أبناء الحداثة أو التحديث يعني هئي أن

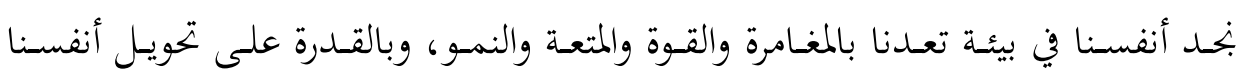

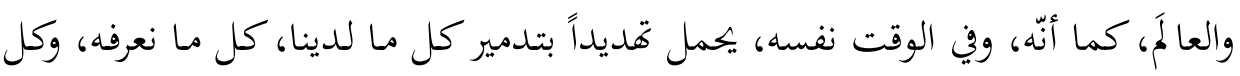




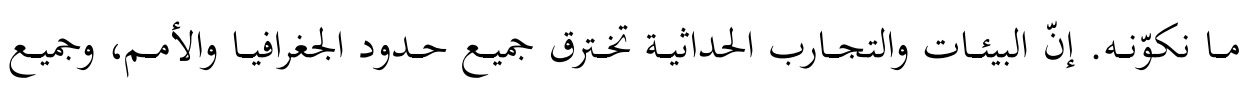
حدود الطبقات والدول، وجميع حدود الأديان والأيديولوجيات. وبهذا المعنى يمكن القول

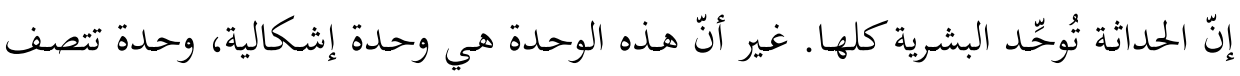

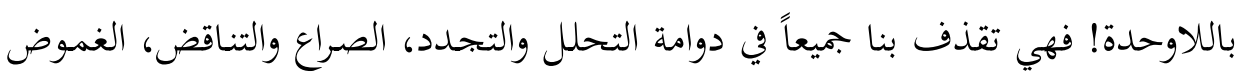

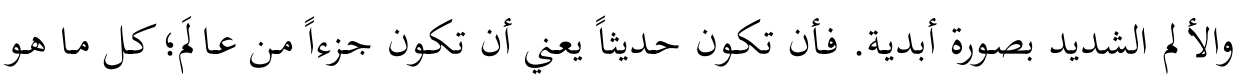

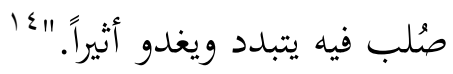

وقـد عبَّرت عـن كل هـذا فلسفات كثيرة معاديـة للعقل والكليـات والمطلقـات، مـن مثل: البرجماتيـة، وفلسفات الحيـاة (برجسون)، ثيّ تلتها الفنومينولوجيـة كنوع مـن محاولة

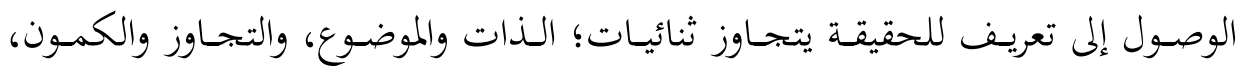

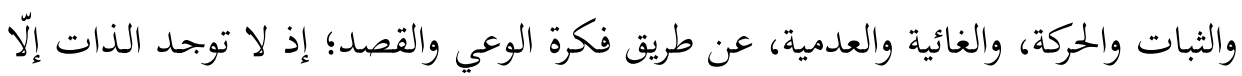

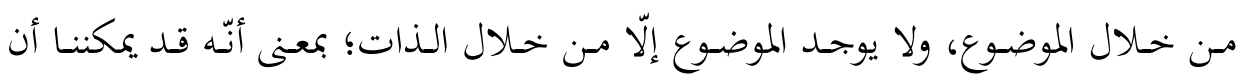
نصل إلى الحقيقة الكلية دون الحاجة إلى بتحاؤز أو ثبات أو غائيات أو ثنائيات. وكأنيّ بهذه الإشارات المركزة بلغت، بقصد أو من دونه، إلى هذه الخلاصة المركبة التي

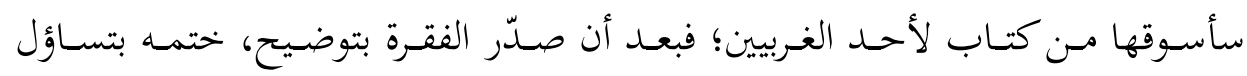
مركزي، فقرر أنّه قبل المضي قُدماً في توضيح ما يرغب في كشف اللثام عنه من مرجعيات

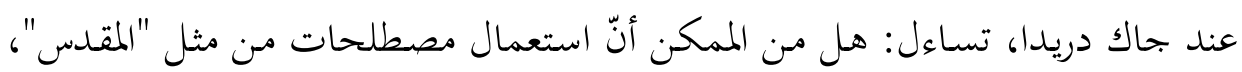

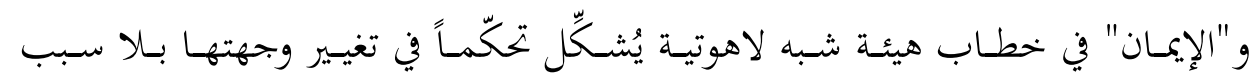

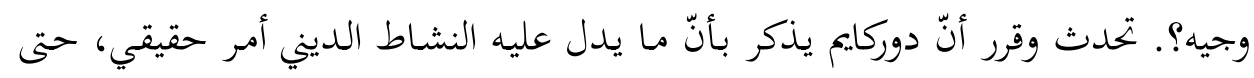

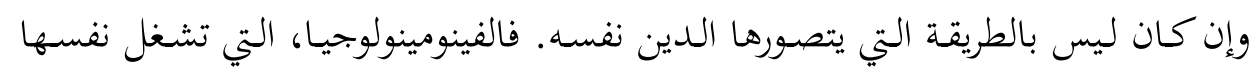

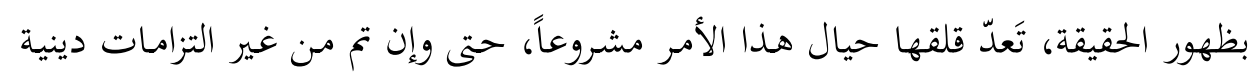

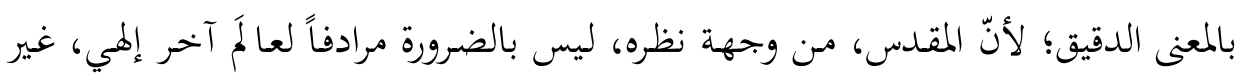

؛' بيرمان، مارشال. حداثة التخلف: تجربة الحداثة، ترجمة: فاضل جتكر، نيقوسيا: مؤسسة عيبال للدراسات

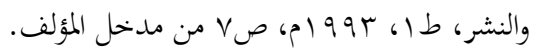

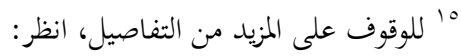
- المسيري، العلمانية الجزئية والعلمانية الشاملة، مرجع سابق، مج المان، صفحات متعددة. 
العالم الدنيوي. فالقضية ليست قضية أنّ عوا لم أخرى غيبية ولاهوتية قد تكون مقدسة،

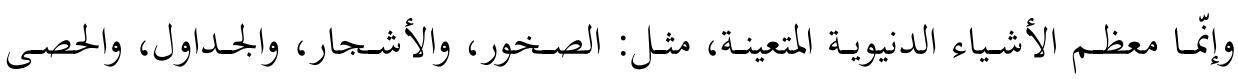
مقدسة أيضاً. 17

أفليست هذه إلّا حلولية مادية كمونية؛ تُسقِط القداسة على العالمَ المادي، وتعرّيه من تواصله مع عالَمهـ المتجاوٍِ؛ أي بتحرده من كونه مخلوقاً لله، ويستحيل أن يحل فيه الله، أو يستغني بقانونه الداخلي بوصفه مرجعيته النهائية، كما يستحيل أن يستغرق ماهيتَه

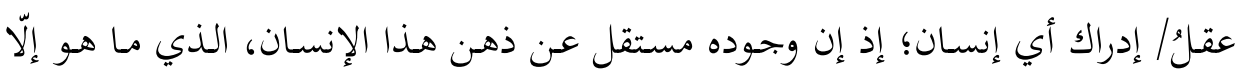

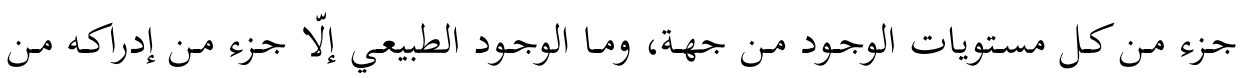
جهة ثانية.

\section{رابعاً: مداخل القراءة المعرفية: كيفيات التجلي}

كنت ذكرت في مقدمة هذه الورقة أنّ المسيري يمتلك نموذجاً معرفيّاً (رؤية معرفية) متماسكاً ينتقل به بين خبايا كل القضايا والظواهر التي يتعرض هلا بالدرس والتحليل؛ أي

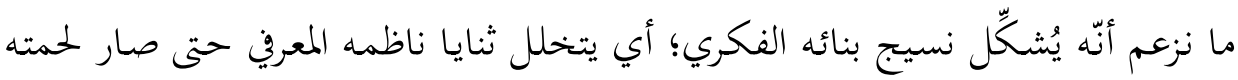

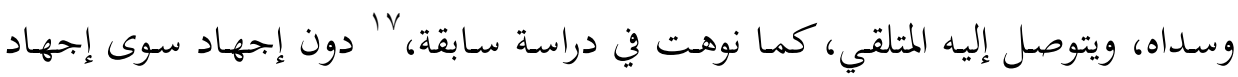
المطالعـة الجهادة، والنظر الفـاحص الـذي لا يتيـه صـاحبه وراء المعلومـات؛ فتستغرقه لأنّهـ يأخذها شذر مذر، ولا يستطيع التركيب ليمسك بالخيط الناظم الذي يلم شعثها. ومن النتائج الفورية لذلك أنّ بعضهم يتساءل مستنكراً: ما علاقة المحاز بالتوحيد؟

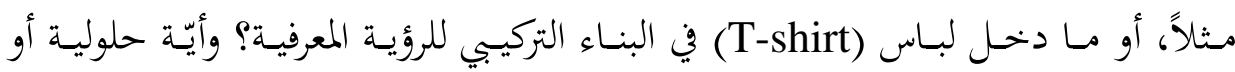
علمانيـة تلحقـه وهـو يستر العورة لا غـير؟ فـأيّ حـديث عـن العلمانيـة، والرؤيـة الكامنـة والتوحيد؟

16 Patrick O'Connor: Derrida: Profanations-Continuum International Publishing Group- The Tower Building 80 Maiden Lane 11 York Road Suite 704 London- New York-2010- p63

$$
\text { Y' مرزاق، التوحيد: كيف ينسج خيوط كتابات عبد الوهاب المسيري؟، مرجع سابق، صبr؟ . }
$$


إنّ التسلح بالقراءة المعرفية هو الذي يجعلنا نحصّل الثمار المرجوة، أمّا قراءة المعلومات

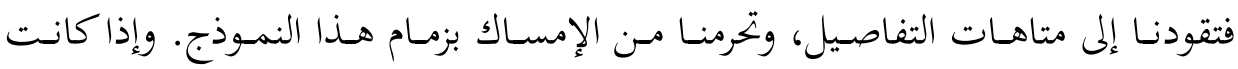

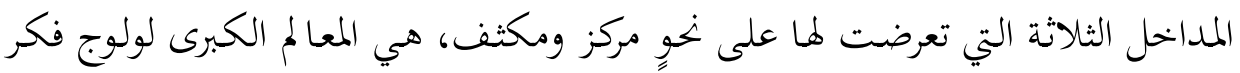

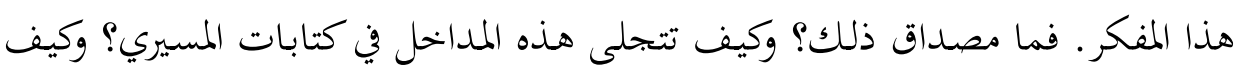

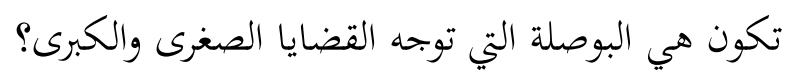
الحق أنتي لن أطيل في سرد هذه التجليات، وإنّما سأكتفي ببعض ما يفي بالغرض فحسب، وهو نصوص منتقاة من المؤلف دون تعليقات مني إلّا ماكان للربط. يـذهب المسـيري إلى أنّ علاقـة الـدالّ بالمــلولول، مـثلاً، ليسـت كمــا قـــ تبـدو بحـرد

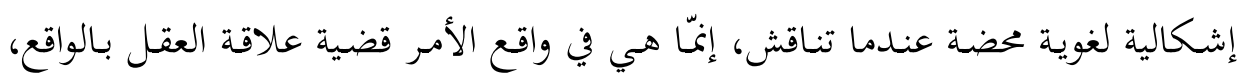

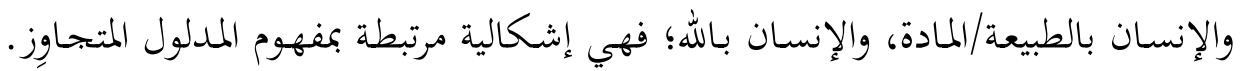

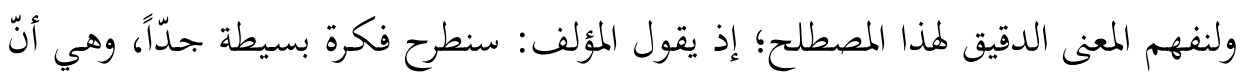

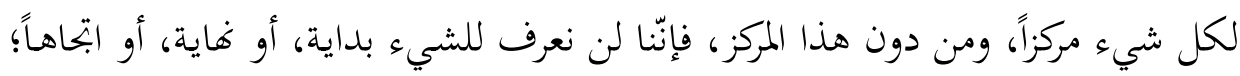

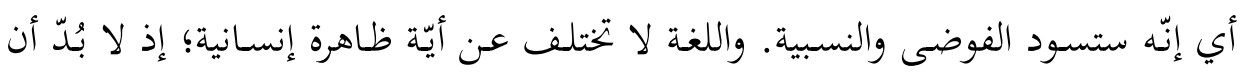

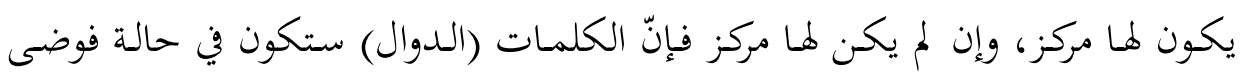

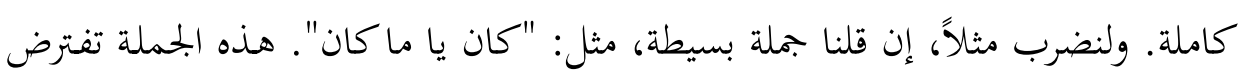

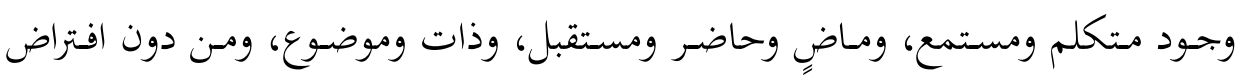

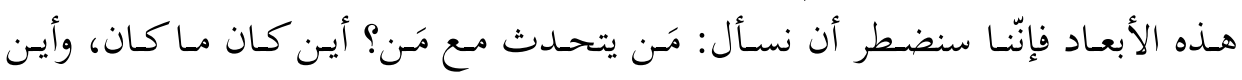

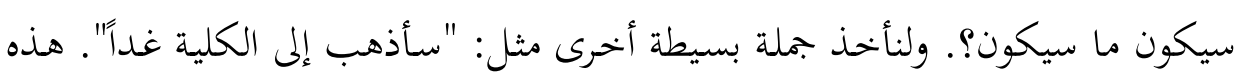

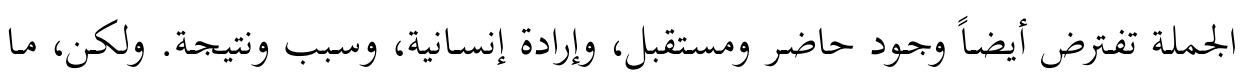

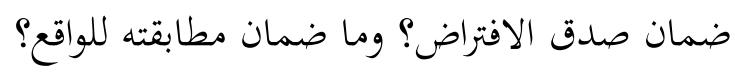
الضـمان الوحيــ هـو وجـود شيء متجــاوِز للحاضـر والمسـتقبل والإرادة الإنسـانية والسبب والنتيجـة، يضمن وجـود هـذه العناصر واستمرارها على الرغم مـن بتحاوزٍ إيّاهـا.

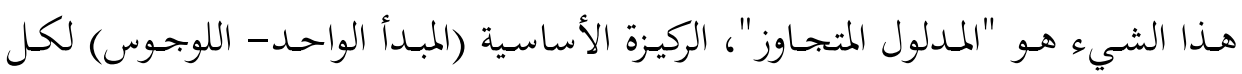

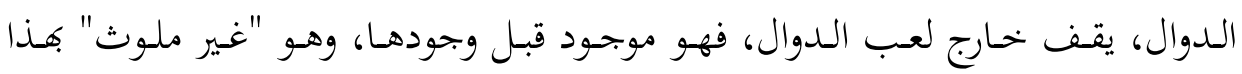




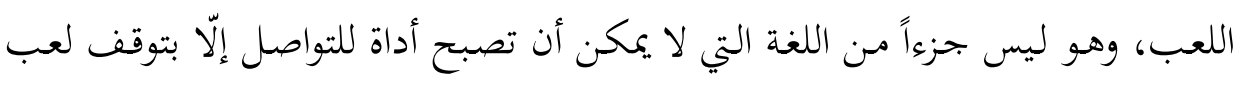

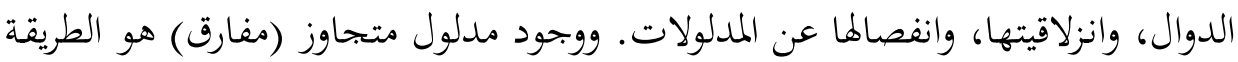

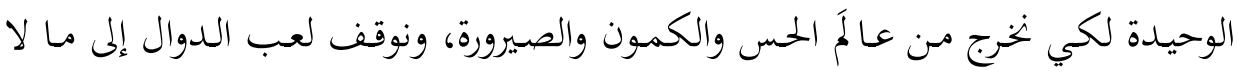

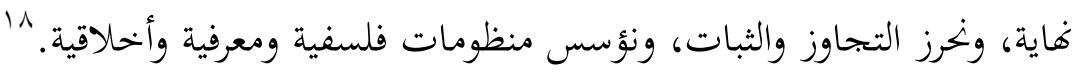
يمكننا في هذا المقام أن نسرد مئات النصوص لنمثّل لما زعمناه، لكنّ ذلك سيضطرنا إلى إعادة كتابة كل مؤلفات المسيري. لذلك، سنمضي إلى تمثيلٍ آخر عن العلمانية، ومن

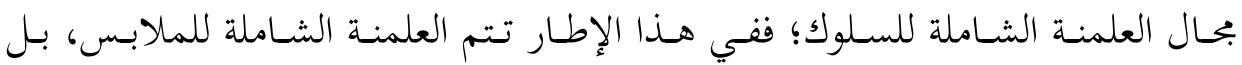

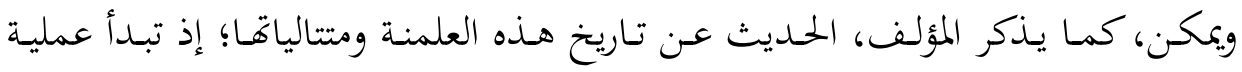

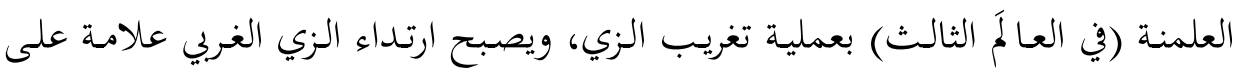

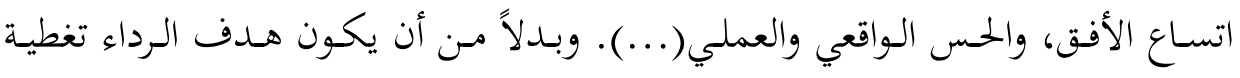

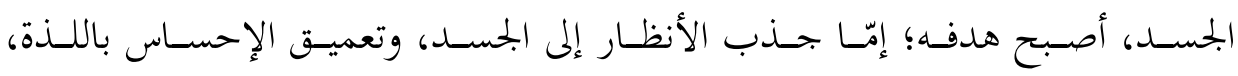

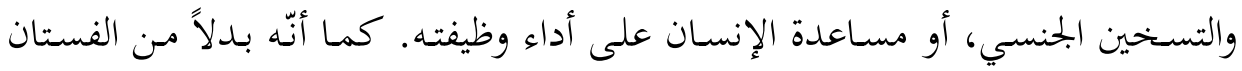

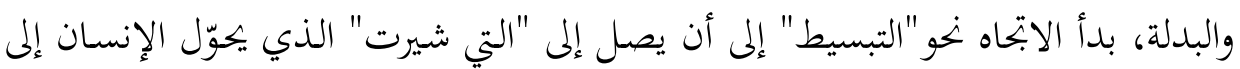

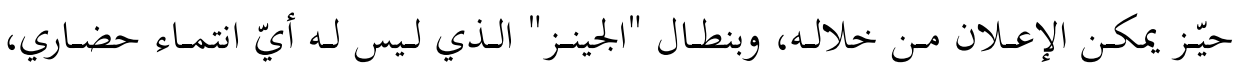

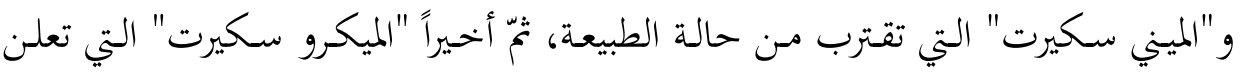

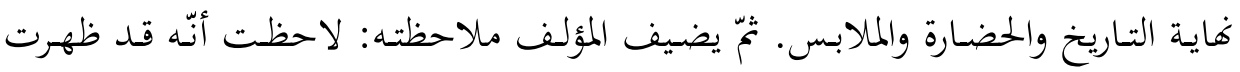

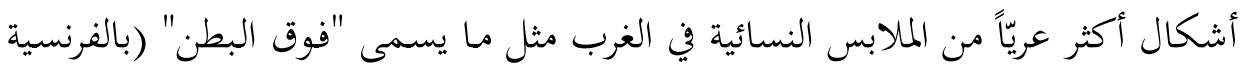
(demi ventre الأفق والتفتح ومواكبة التطور !.

ومفهوم التقاليع (الموضة) يُعَدّ من أهم آليات العلمنة؛ فالتقاليع تعني التغيير الدائم، والتطلع نحو الاستهالك، وهي بتحد رؤية العالم كمادة متحركة وآلية كبرى للترانسفير. 19

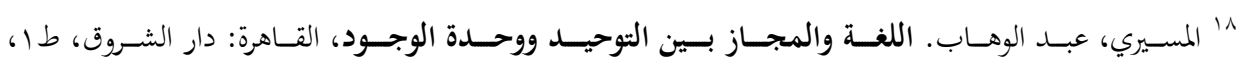

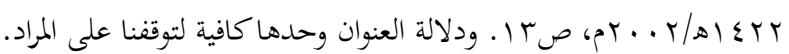

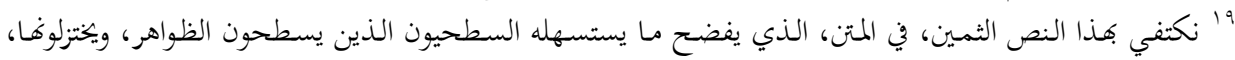

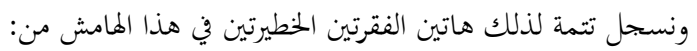


عندما يقول أحد نقاد الأدب أو مبدعيه، والأدب للتمثيل فحسب، عن الرومانسي

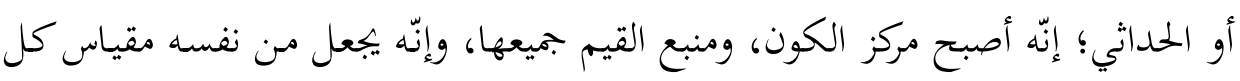

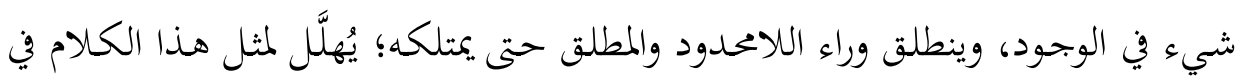

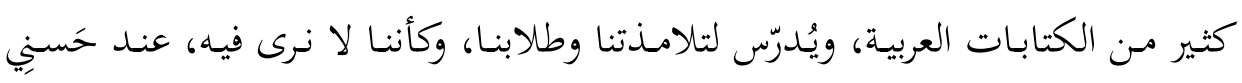

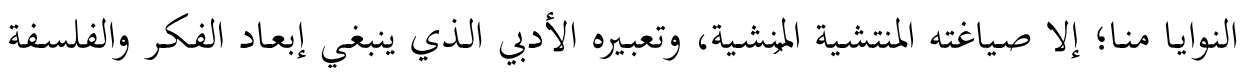

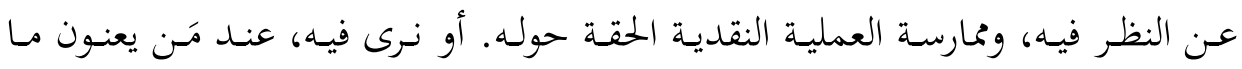

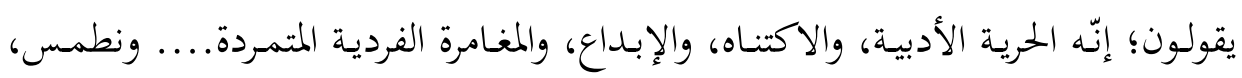

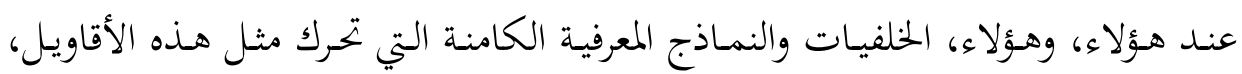

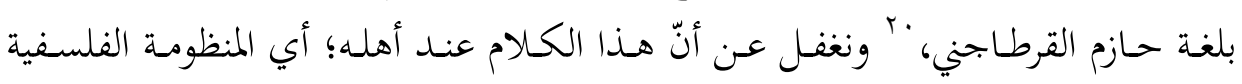

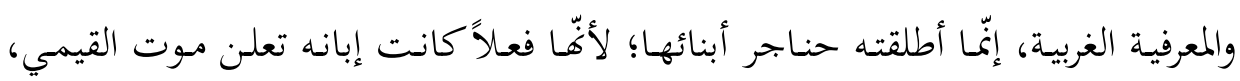

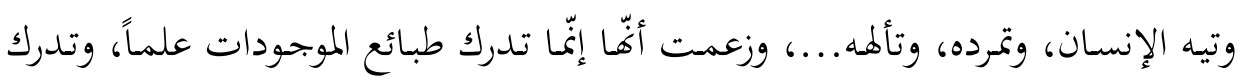
قيمها عملاً، ناسية أنّ ذلك فوق طورها، وأنّه طمع في محال. ونغفل عن أنّ ذلك عند كثير من أصحاب التبعية من أهلنا، إنّّا أطلقته حناجرهم

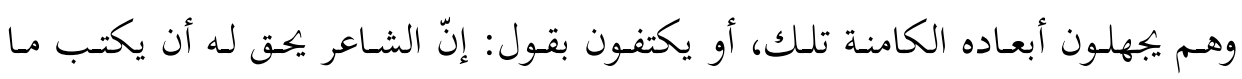

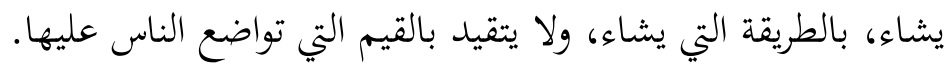

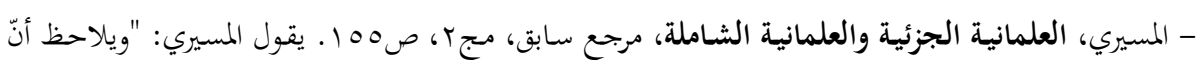

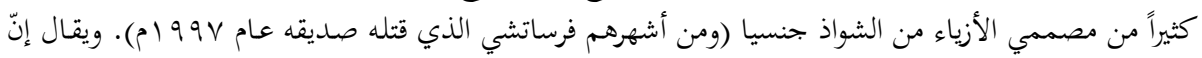

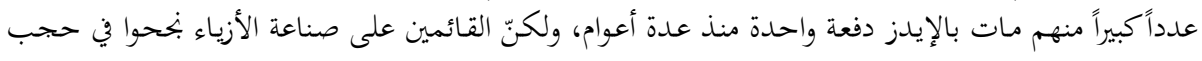

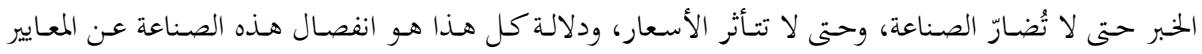

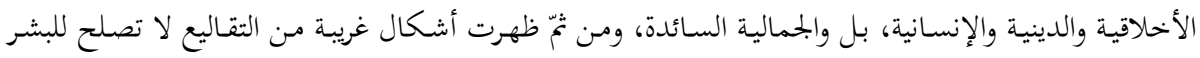

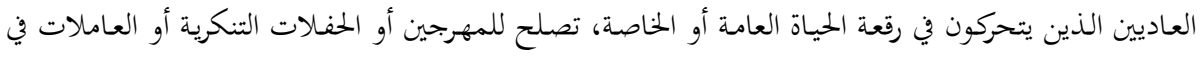

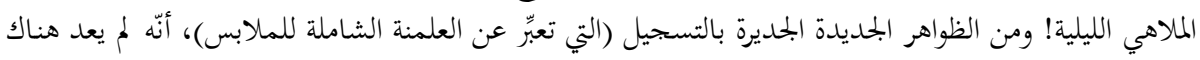

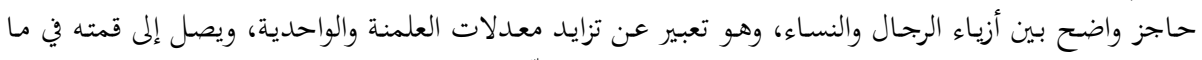

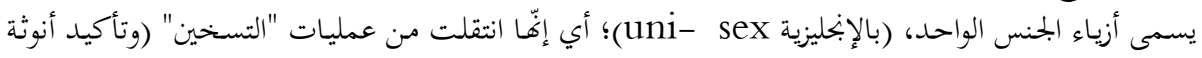

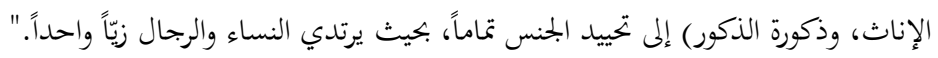

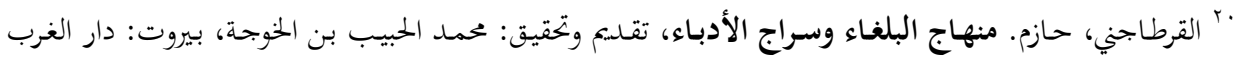

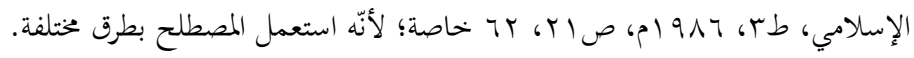


عند هذا الحـد من طرق التفكير المختزِلة جمّاعة المعلومـات؛ لا بُدّّ مـن الإعلان عن

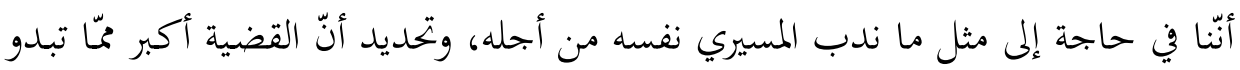

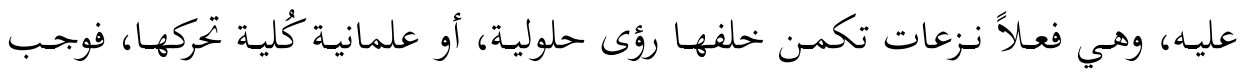

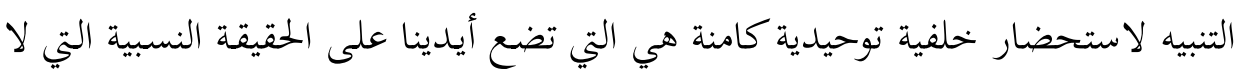

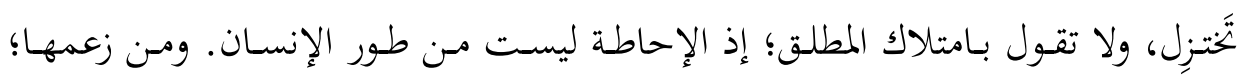

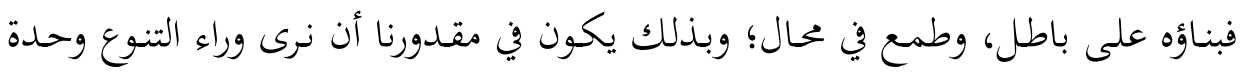

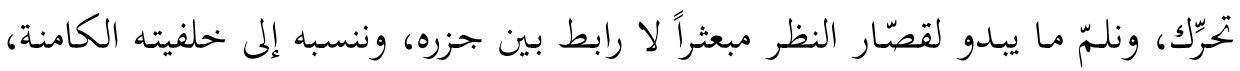

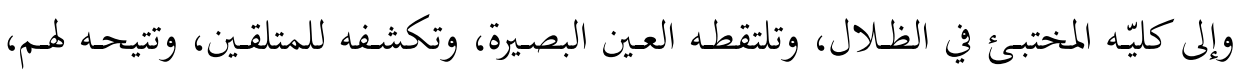

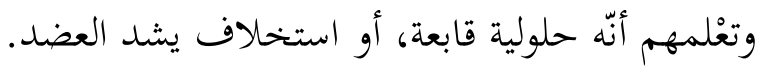

